\title{
A CORRESPONDÊNCIA ENTRE OBJETOS DE APRENDIZAGEM E MAPAS CONCEITUAIS: UMA REVISÃO SISTEMÁTICA DA LITERATURA
}

\section{THE CORRESPONDENCE BETWEEN LEARNING OBJECTS AND CONCEPTUAL MAPS: A SYSTEMATIC REVIEW OF LITERATURE}

\author{
Renata Oliveira da Silva $1^{1}$, mestranda \\ Luziana Quadros da Rosa ${ }^{2}$, mestranda \\ Lucyene L S T Nunes ${ }^{3}$, doutoranda \\ Marcio Vieira de Souza ${ }^{4}$, doutor \\ (1) Universidade Federal de Santa Catarina \\ e-mail: renatadasilvatpg@gmail.com \\ (2) Universidade Federal de Santa Catarina \\ e-mail: cpead.bpi.luziana@gmail.com \\ (3) Instituto Federal Catarinense \\ e-mail: lucyene.nunes@sombrio.ifc.edu.br \\ (4) Universidade Federal de Santa Catarina \\ e-mail: marciovieiradesouza@gmail.com
}

Palavras-chave: Objetos de Aprendizagem, mapa conceitual, aprendizagem personalizada.

Resumo: O objetivo deste artigo é identificar a relação entre Objetos de Aprendizagem e mapas conceituais na elearning. Realizou-se uma revisão sistemática nas bases de periódicos Capes e IEEE Xplore. Das 108 publicações identificadas, selecionaram-se sete obras, evidenciando-se que a relação está no acesso mais personalizado de estudantes à aprendizagem.

\section{Key-words: Learning Objects, Conceptual Map, Personalized Learning.}

Abstract: The objective of this article is to identify the relation between learning objects and concept maps in elearning. It was performed a systematic review in Capes and IEEE Xplore. Of the 108 publications identified, were selected seven papers, showing that the relation is in the students' more personalized access to learning.

\section{Introdução}

O uso das Tecnologias da Informação e
Comunicação (TIC) torna-se necessário na aprendizagem para a construção do conhecimento. Deste modo, recursos pedagógicos como os Objetos de Aprendizagem (OA) são utilizados 


\section{$16^{\circ}$ \\ ERGODESIGN USIHC CINAHPA}

como artefatos para despertar o interesse dos estudantes na educação formal e informal. No desenvolvimento de projetos pedagógicos que incluem os OA uma ferramenta que pode ser utilizada são os mapas conceituais. Pois, os mapas conceituais potencializam a criação de uma imagem da estrutura conceitual que se deseja representar [OKADA, 2007], bem como, indicam relações entre conceitos apresentados [MOREIRA, 2012].

No entanto, a literatura existente pouco apresenta a correspondência entre estes dois recursos, OA e mapas conceituais. Cabe, deste modo, uma investigação científica que possa demonstrar as publicações que relacionam estes temas, visto que alguns autores reforçam a utilização de mapas conceituais para uma aprendizagem significativa [MOREIRA, 2012; RODRIGUES E BARNI, 2009; OKADA, 2014].

Assim, o objetivo do estudo é identificar a relação entre os OA e mapas conceituais, na e-learning, nas publicações científicas disponibilizadas em duas bases de dados: Portal de Periódicos da Capes e IEEE XPlore Digital Library. O conceito de $e$ learning é colocado na perspectiva de Gomes [2005, p. 232] como "como uma extensão da sala no espaço virtual da internet (ou outros ambientes de rede)".

Para isto, como metodologia da pesquisa, empregase uma RSL (Revisão Sistemática da Literatura). Deste modo, a presente pesquisa está estruturada da seguinte maneira: no referencial teórico são expostos conceitos básicos introdutórios sobre os OA e mapas conceituais. Dando continuidade ao artigo, são apresentados os procedimentos metodológicos, seguidos da discussão e análise dos resultados encontrados a partir da RSL, e por fim, são evidenciadas as considerações finais.

\section{Impulsionando a aprendizagem com OA e mapas conceituais}

\subsection{Objetos de Aprendizagem}

$16^{\circ}$ Ergodesign - Congresso Internacional de Ergonomia e Usabilidade de Interfaces Humano Tecnológica: Produto, Informações Ambientes Construídos e Transporte

$16^{\circ}$ USIHC - Congresso Internacional de Ergonomia e Usabilidade de Interfaces Humano Computador

CINAHPA | 2017 - Congresso Internacional de Ambientes Hipermídia para Aprendizagem.

Audino e Nascimento [2010, p. 141] conceituam os OA como "recursos digitais dinâmicos, interativos e reutilizáveis em diferentes ambientes de aprendizagem elaborados a partir de uma base tecnológica".

Para Churchill [2007] o OA pode ser designado como a representação planejada que permite seu uso em diferentes conceitos educacionais. Bettio e Martins [2003] apud Ferreira e Rezende [2013] definem que os OA apresentam em sua estrutura elementos importantes que os caracterizam e potencializam, como exemplo: dispõem de flexibilidade (reusável), apresentam padrões abertos que favorecem a customização, contam com a interoperabilidade e então são reutilizados em diferentes contextos e plataformas, além de fáceis de serem encontrados devido ao seu tipo de indexação. Além disso, os autores, citados anteriormente, definem que os OA têm como ponto positivo o seu baixo custo, a fácil manutenção, a frequente atualização, o trabalho colaborativo, etc.

Macedo [2010] compreende os OA como um conteúdo particular e como objeto de informação, possuindo um objetivo de aprendizado mensurável e bem definido em que sua disponibilização pode ocorrer na web, em ambientes de aprendizagem ou em repositórios específicos. Por sua vez, os metadados estabelecem as informações de um OA, assim contribuem para a reutilização e interoperabilidade desse recurso nas distintas plataformas do contexto educacional [MENOLLI et al, 2014].

Para se criar um OA é necessário um planejamento que demanda técnicas que devem ser desenvolvidas, implementadas e posteriormente avaliadas. Deste modo, Maeda et al [2005] apud Ferreira e Rezende [2013] apresentam as etapas de elaboração de OA que foram utilizadas em suas investigações, e que são listadas a seguir, servindo de base para um modelo de execução de OA:

1) Processo de escolha do tema, ou seja, do objetivo que se pretende com o OA;
Realização:
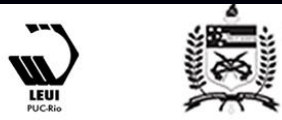


\section{$16^{\circ}$ \\ ERGODESIGN USIHC CINAHPA}

2) Definições de como deve ser o OA, podendo usar um projeto explicativo para as definições do objeto;

3) Análise de viabilidade do projeto, supervisionada por quem o desenvolverá, para se ter continuidade do mesmo;

4) Execução do projeto, ou seja, construção do $\mathrm{OA}$;

5) Testes e avaliações com o OA em uso;

6) Compartilhamento do projeto.

Assim, é possível definir que todo OA demanda um planejamento que parte de uma demanda até a sua avaliação após executado. Deste modo, é preciso respeitar todas as etapas de criação do OA para que o resultado final seja satisfatório. De início, a criação de um OA parte de uma demanda existente que pode ser pesquisada previamente com o público alvo. Por conseguinte, cria-se um esboço com as características que o objeto precisa apresentar, bem como a proposta que ele almeja alcançar. Na continuidade, esse primeiro projeto será analisado pelos executores e sofrerá as mudanças necessárias antes da aplicação. Desta maneira, passa-se para a fase de execução prática. Após, o OA e sua aplicação serão avaliados para receberem as melhorias antes de serem compartilhados. O compartilhamento em uma plataforma aberta, preferencialmente, deve ser divulgado para que outros profissionais conheçam o OA e tenham o acesso facilitado para fomentar o reuso e atualização desse objeto [FERREIRA e REZENDE, 2013].

\subsection{Mapas conceituais, mentais e cognitivos}

Nesta sessão, buscamos apresentar os conceitos que distinguem as nomenclaturas dos mapas conceituais, mentais e cognitivos.

Para Okada e Santos [2005] mapas conceituais são técnicas que estabelecem relações entre conceitos e conhecimentos significativos, podendo contemplar diversas áreas do conhecimento, $16^{\circ}$ Ergodesign - Congresso Internacional de Ergonomia e Usabilidade de Interfaces Humano Tecnológica: Produto, Informações Ambientes Construídos e Transporte

$16^{\circ}$ USIHC - Congresso Internacional de Ergonomia e Usabilidade de Interfaces Humano Computador

CINAHPA | 2017 - Congresso Internacional de Ambientes Hipermídia para Aprendizagem.

utilizados no auxílio de uma ordenação hierarquizada.

Os mapas mentais são técnicas que, assim como a nossa mente, permitem o registro do pensamento de forma mais criativa, flexível e não-linear [OKADA e SANTOS, 2005].

Ainda, entende-se como mapa cognitivo "a representação gráfica multilinear, compacta e dinâmica do pensamento não linear, abstrato $\mathrm{e}$ sempre em fluxo que permite exteriorizar elementos e suas relações do mundo mental facilitando sua compreensão através da desconstrução-reconstrução em níveis mais elevados de diversidade, coerência, consistência e clareza" [OKADA, 2006, p. 77].

\subsection{Mapa cognitivo difuso}

Neste item descreve-se o conceito sobre mapa cognitivo difuso no intuito de contribuir com o entendimento do trabalho.

Os mapas cognitivos difusos (MCD), do inglês Fuzzy Cognitive Maps (FCM), constituem-se em um instrumento para a modelação do conhecimento humano, alcançado através de preceitos linguísticos, próprios aos sistemas difusos, contudo com um arcabouço análogo à das Redes Neurais Artificiais (RNA), expondo, consequentemente habilidade de treinamento e adaptação [MENDONÇA; ARRUDA; NEVES JR, 2009].

Para Pacheco [2005] o mapa cognitivo difuso apoia-se nas variadas relações de causa e efeito de um sistema complexo, forma uma rede de informações representando o sistema objeto de análise, desta forma, considera-se um método de modelagem matemática que permite a aquisição relevante de aspecto de um sistema, além de obter diagnósticos e prognósticos.

A derivação da lógica Fuzzy surgiu com a publicação do artigo "Fuzzy Sets" (ou conjuntos fuzzy) do professor Zadeh, da Universidade de Berkeley, na Califórnia. A lógica fuzzy é um superconjunto da lógica convencional (Booleana), 


\section{$16^{\circ}$ \\ ERGODESIGN USIHC CINAHPA}

cuja extensão permite representar o conceito de verdade parcial [VON RAESFELD-PORRAS, 2000].

\section{Procedimentos Metodológicos}

Nesta pesquisa optou-se pelo uso de uma Revisão Sistemática da Literatura (RSL) por ser um método de seleção e análise rigoroso de dados [COCHRANE, 2017]. Inicialmente formulou-se uma questão objetiva para nortear a pesquisa: qual a relação entre Objetos de Aprendizagem e mapas conceituais?

$\mathrm{Na}$ etapa sequente, foram seguidas três fases distintas propostas por Silva e Spanhol [2013] e denominada de "tríade da busca sistemática", que contemplam as fases de coleta, análise e resultados da RSL.

\subsection{Primeira fase: coleta}

Na primeira fase, na qual constitui-se a etapa de seleção das bases de dados optou-se pelo uso de bases significativas da realidade acadêmica que apresentam o tema das tecnologias na educação. Deste modo, a base Portal de Periódicos da Capes teve importante papel nas buscas, uma vez que abrangia resultados de inúmeras bases importantes, como Scopus e ERIC, bases de maior relevância, que apresentam conteúdos na temática selecionada. Ainda, escolheu-se a base IEEE XPlore Digital Library, pois é uma conceituada base internacional e, portanto, traz resultados meritórios ao estudo.

Ainda nesta fase, foram realizadas duas novas etapas da tríade da busca sistemática, definindo os termos de busca e determinando uma estratégia de busca nas bases selecionadas.

Como critério, utilizou-se os mesmos termos, nos idiomas português e inglês, em todas as bases utilizadas, como mostrado nos Quadro 1 e Quadro 2.

\begin{tabular}{|c|c|}
\hline Termo & Objeto de Aprendizagem \\
\hline Operador booleano & AND \\
\hline
\end{tabular}

$16^{\circ}$ Ergodesign - Congresso Internacional de Ergonomia e Usabilidade de Interfaces Humano Tecnológica: Produto, Informações Ambientes Construídos e Transporte

$16^{\circ}$ USIHC - Congresso Internacional de Ergonomia e Usabilidade de Interfaces Humano Computador

CINAHPA | 2017 - Congresso Internacional de Ambientes Hipermídia para Aprendizagem.

\begin{tabular}{|c|c|}
\hline Termo & mapa conceitual \\
\hline Operador booleano & OR \\
\hline Termo & $\begin{array}{c}\text { mapa mental } \\
\text { mapa cognitivo }\end{array}$ \\
\hline
\end{tabular}

Quadro 01: termos buscados na língua portuguesa Fonte: autores

\begin{tabular}{|c|c|}
\hline Termo & Learning Object \\
\hline Operador booleano & AND \\
\hline Termo & conceptual map \\
\hline Operador booleano & OR \\
\hline Termo & $\begin{array}{c}\text { mental map } \\
\text { cognitive map }\end{array}$ \\
\hline
\end{tabular}

Quadro 02: termos buscados na língua inglesa Fonte: autores

Além disso, sucedeu-se a definição dos tipos de publicações e áreas dos estudos, na qual se optou por artigos científicos de abrangência nacional e internacional, como artigos completos, entre outras produções bibliográficas advindas também de eventos e revistas dentro da temática da tecnologia educacional, na área das Ciências Humanas. Como critérios de inclusão, definiu-se a seleção de artigos que contemplassem os termos, supracitados nos Quadros 01 e 02, em seus títulos, resumos e palavras-chave. Ainda nesta etapa, incluíram-se as publicações existentes no período do ano de 2007 ao primeiro bimestre de 2017. Como critérios de exclusão, não foram selecionadas publicações em período distinto ao definido, trabalhos de outras áreas temáticas e livros e capítulos de livros foram dispensados.

Como estratégia de pesquisa, foi necessária a transformação das palavras de busca para que os resultados apresentassem também as variações dos sufixos. Além disso, foram utilizados caracteres para melhor refinar a busca, tais como: " (aspas) e * (asterisco). Nas bases, supracitadas, utilizadas nessa pesquisa foram realizadas 6 buscas diferentes para contemplar todos os termos definidos nos Quadros 01 e 02. 


\section{$16^{\circ}$ \\ ERGODESIGN USIHC CINAHPA}

Para melhor definir essas buscas, tanto no idioma inglês, quanto português, o Quadro 03 representa:

\begin{tabular}{|c|c|c|}
\hline Base & $\begin{array}{c}\text { Idioma das } \\
\text { palavras da busca }\end{array}$ & Termos utilizados \\
\hline CAPES & Inglês & $\begin{array}{l}\text { "Learning* Object*" AND } \\
\text { "concept* map*" }\end{array}$ \\
\hline CAPES & Inglês & $\begin{array}{l}\text { "Learning* Object*" AND } \\
\text { "ment* map*" }\end{array}$ \\
\hline CAPES & Inglês & $\begin{array}{l}\text { "Learning* Object*" AND } \\
\text { "cognit* map*" }\end{array}$ \\
\hline CAPES & Português & $\begin{array}{c}\text { "Objeto* de } \\
\text { Aprendizagem*" AND } \\
\text { "map* conceitua*" }\end{array}$ \\
\hline CAPES & Português & $\begin{array}{c}\text { "Objeto* de } \\
\text { Aprendizagem*" AND } \\
\text { "map* menta*" }\end{array}$ \\
\hline CAPES & Português & $\begin{array}{c}\text { "Objeto* de } \\
\text { Aprendizagem*" AND } \\
\text { "map* cogni*" }\end{array}$ \\
\hline IEEE & Inglês & $\begin{array}{l}\text { "Learning Object" AND } \\
\text { "conceptual map" }\end{array}$ \\
\hline IEEE & Inglês & $\begin{array}{l}\text { "Learning Object" AND } \\
\text { "mental map" }\end{array}$ \\
\hline IEEE & Inglês & $\begin{array}{l}\text { "Learning Object" AND } \\
\text { "cognitive map" }\end{array}$ \\
\hline IEEE & Português & $\begin{array}{l}\text { "Objeto de Aprendizagem" } \\
\text { AND "mapa conceitual" }\end{array}$ \\
\hline IEEE & Português & $\begin{array}{l}\text { "Objeto de Aprendizagem" } \\
\text { AND "mapa mental" }\end{array}$ \\
\hline IEEE & Português & $\begin{array}{l}\text { "Objeto de Aprendizagem" } \\
\text { AND "mapa cognitivo" }\end{array}$ \\
\hline
\end{tabular}

Quadro 3: Palavras e caracteres utilizados nas buscas das bases acadêmicas

Fonte: autores

Seguindo as estratégias para refinar as buscas, na base "CAPES" escolheu-se que as buscas fossem apenas por artigos, que os mesmos fossem dos últimos 10 anos (data selecionada 01/01/2007 a $15 / 03 / 2017$ ) e que fossem revisados por pares. $\mathrm{Na}$ base "CAPES", quando utilizada a combinação "Learning* Object*" AND "concept* map*" $16^{\circ}$ Ergodesign - Congresso Internacional de Ergonomia e Usabilidade de Interfaces Humano Tecnológica: Produto, Informações Ambientes Construídos e Transporte

$16^{\circ}$ USIHC - Congresso Internacional de Ergonomia e Usabilidade de Interfaces Humano Computador

CINAHPA | 2017 - Congresso Internacional de Ambientes Hipermídia para Aprendizagem. definiu-se que, além dos critérios anteriormente citados, se restringisse também a temática "concept map". Nas delimitações da base "IEEE" foram considerados somente artigos da base IEEE, pesquisados apenas nas revistas e publicações em eventos, de 2007 até o presente período (primeira quinzena de março/2017).

Após essa fase, inicia-se uma etapa de análise das publicações, na qual utiliza-se o software Endnote para organizar as referências e excluir as duplicações. Apresenta-se, deste modo, a etapa de identificação e organização da amostra inicial.

Depois de definidas as delimitações, as buscas foram realizadas nas bases e totalizaram 110 artigos encontrados. Sendo 95 artigos da base "CAPES" e 15 artigos da base "IEEE". Na base "CAPES" foram encontradas 2 duplicações quando utilizados os termos "Learning * Object*" AND "ment* map*" e "Learning* Object*" AND "cognit* map*". Portanto, essas duplicações foram excluídas da contagem final dos artigos, restando 108 publicações.

\subsection{Segunda fase: Análise}

Nesta fase, contemplamos três etapas distintas, propostas por Silva e Spanhol [2013], previstas na tríade de análise sistemática, a saber: etapa de seleção dos trabalhos segundo critérios pré-definidos, etapa de identificação dos trabalhos disponíveis para consulta e a etapa de seleção dos trabalhos que atendem ao objetivo da pesquisa.

\subsection{Terceira fase: Resultado}

A última fase abrange as três últimas etapas da RSL, descritas na etapa de análise bibliométrica dos dados, bem como na etapa de descrição qualitativa dos trabalhos e por fim, a etapa de compilação dos dados, de modo a atender ao objetivo proposto na pesquisa.

Os resultados da segunda e terceira fase estão descritos na seção seguinte desta pesquisa.
Realização:

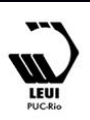




\section{$16^{\circ}$ \\ ERGODESIGN USIHC CINAHPA}

\section{Análise e Discussão dos Resultados}

Para realizar a seleção de artigos correspondentes a temática definida para essa pesquisa, a relação entre OA e mapas conceituais, foi necessária a leitura dos 108 resumos de artigos, bem como a leitura dos títulos e palavras-chave das pesquisas encontradas. Da totalidade, 93 publicações da base Capes e 15 publicações da base IEEE foram selecionados nos requisitos delimitados, na questão norteadora da pesquisa.

Ainda, observou-se que na maioria das 108 publicações encontradas, os termos estavam desconexos, ou seja, sem correspondências. Alguns artigos apresentavam apenas temáticas sobre $\mathrm{OA}$ e outros traziam apenas definições e aplicações de mapas conceituais (mentais ou cognitivos) em sala de aula. Também, é importante destacar que grande parte dos artigos não foram selecionados, pois eram da área da saúde e traziam na sua abordagem conceitos sobre cognição, apresentando estudos laboratoriais com humanos e seres vivos conotados a incentivos para ser estudada a aprendizagem adaptativa. Portanto, sem relação ao objetivo principal proposto nesta pesquisa.

Considerou-se assim, a leitura completa de 15 artigos identificados entre os 108 selecionados, que atendiam previamente o escopo da pesquisa, para mais uma vez, selecionar aqueles que correspondiam estritamente com o objetivo proposto, excluindo os que não apresentavam uma relação clara e bem definida da temática levantada neste estudo.

Portanto, na primeira busca refinada, foram selecionados 15 artigos para continuidade na pesquisa. Após, na segunda leitura de seleção, foram selecionados sete artigos, os quais foram lidos os trabalhos na íntegra. O Quadro 4 apresenta a relação com o tema, os autores, títulos, o ano e a base da publicação, identificadas nos sete artigos encontrados na análise final. $16^{\circ}$ Ergodesign - Congresso Internacional de Ergonomia e Usabilidade de Interfaces Humano Tecnológica: Produto, Informações Ambientes Construídos e Transporte

$16^{\circ}$ USIHC - Congresso Internacional de Ergonomia e Usabilidade de Interfaces Humano Computador

CINAHPA | 2017 - Congresso Internacional de Ambientes Hipermídia para Aprendizagem.

\begin{tabular}{|c|c|c|}
\hline $\begin{array}{c}\text { Ano da } \\
\text { Publicação } \\
\text { e Base }\end{array}$ & Relação com o tema & $\begin{array}{c}\text { Título do trabalho e } \\
\text { Autor (es) }\end{array}$ \\
\hline $\begin{array}{c}2008 \\
\text { CAPES }\end{array}$ & $\begin{array}{l}\text { Uso de mapas } \\
\text { conceituais para a } \\
\text { aprendizagem } \\
\text { adaptativa em } e \text { - } \\
\text { learning. }\end{array}$ & $\begin{array}{l}\text { Mining e-Learning } \\
\text { domain concept map } \\
\text { from academic } \\
\text { articles } \\
\text { (Chen, N. S.; } \\
\text { Kinshuk, C.W.; Wei, } \\
\text { H.J.; Chen, H.J.) }\end{array}$ \\
\hline $\begin{array}{l}2009 \\
\text { IEEE }\end{array}$ & $\begin{array}{l}\text { Recomendação } \\
\text { personalizadas em } \\
\text { sites e-learning. }\end{array}$ & $\begin{array}{c}\text { A Cognition } \\
\text { Inference-Based } \\
\text { Approach for } \\
\text { Learning Object } \\
\text { Recommendation in } \\
\text { E-Learning } \\
\text { (Yan, C.) }\end{array}$ \\
\hline $\begin{array}{c}2009 \\
\text { CAPES }\end{array}$ & $\begin{array}{l}\text { Representação } \\
\text { ontológicas para } \\
\text { aprendizagem por } \\
\text { meio de OA. Em sua } \\
\text { proposta, visam a } \\
\text { navegação } \\
\text { diferenciada para o } \\
\text { perfil cognitivo do } \\
\text { aluno e suas } \\
\text { percepções, } \\
\text { expectativas e } \\
\text { experiências } \\
\text { anteriores. }\end{array}$ & $\begin{array}{l}\text { CogSkillnet: An } \\
\text { Ontology-Based } \\
\text { Representation of } \\
\text { Cognitive Skills } \\
\text { (Askar, P.; Altun, } \\
\text { A.) }\end{array}$ \\
\hline $\begin{array}{c}2010 \\
\text { CAPES }\end{array}$ & $\begin{array}{l}\text { Apresentação } \\
\text { conceitos de mapas } \\
\text { cognitivos através do } \\
\text { Fuzzy Cognitive Map, } \\
\text { com ênfase na } \\
\text { qualificação das } \\
\text { informações dos } \\
\text { mapas. }\end{array}$ & $\begin{array}{c}\text { A divide and } \\
\text { conquer method for } \\
\text { learning large Fuzzy } \\
\text { Cognitive Maps } \\
\\
\text { (Stach, W.; Kurgan, } \\
\text { L.; Pedrycz, W.) }\end{array}$ \\
\hline $\begin{array}{l}2012 \\
\text { IEEE }\end{array}$ & $\begin{array}{l}\text { Utilização de mapas } \\
\text { cognitivos na } \\
\text { aprendizagem, como } \\
\text { exemplo, um Fuzzy } \\
\text { Cognitive Map (FCM). }\end{array}$ & $\begin{array}{l}\text { A curious learning } \\
\text { companion in } \\
\text { Virtual Learning } \\
\text { Environment } \\
\text { (Wu, Q., Miao, C. e } \\
\text { Chen, Z) }\end{array}$ \\
\hline $\begin{array}{c}2012 \\
\text { CAPES }\end{array}$ & $\begin{array}{l}\text { Proposta de } \\
\text { aprendizagem híbrida, } \\
\text { baseada em Objetos de } \\
\text { Aprendizagem. O } \\
\text { principal recurso } \\
\text { utilizado nesta } \\
\text { proposta são os mapas } \\
\text { conceituais. }\end{array}$ & $\begin{array}{c}\text { Web-based learning } \\
\quad \text { design tool } \\
\text { (Bruno, F.B.; Silva; } \\
\text { T.L.K.; Silva, R.P.; } \\
\text { Teixeira, F.G.) }\end{array}$ \\
\hline $\begin{array}{c}2016 \\
\text { CAPES }\end{array}$ & $\begin{array}{l}\text { Proposta voltada aos } \\
\text { alunos, através de } \\
\text { conceitos mistos. }\end{array}$ & $\begin{array}{c}\text { Personalized } \\
\text { Recommendation; E- } \\
\text { Learning; Immune }\end{array}$ \\
\hline
\end{tabular}




\section{$16^{\circ}$ \\ ERGODESIGN USIHC CINAHPA}

$16^{\circ}$ Ergodesign - Congresso Internacional de Ergonomia e Usabilidade de Interfaces Humano Tecnológica: Produto, Informações Ambientes Construídos e Transporte

$16^{\circ}$ USIHC - Congresso Internacional de Ergonomia e Usabilidade de Interfaces Humano Computador

CINAHPA | 2017 - Congresso Internacional de Ambientes Hipermídia para Aprendizagem.

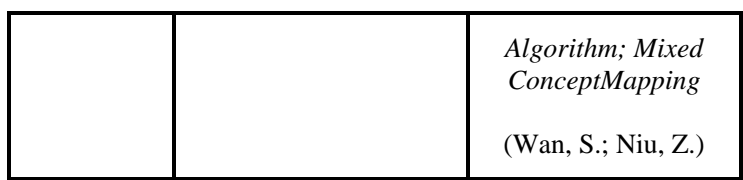

Quadro 4: Publicações sobre o tema Fonte: autores

\subsection{A correspondência entre os $\mathrm{OA}$ e os mapas conceituais}

Dos artigos selecionados, Chen et al [2008] trazem em seu estudo pesquisas que demonstram a importância dos mapas conceituais e suas aplicações na $e$-learning, como a representação gráfica de conhecimento de domínio, facilitando a produção de materiais de aprendizagem adaptativa e principalmente orientando a aprendizagem dos estudantes, para que estes não recebam um excesso de informações de conteúdo. Na proposta recomendada pelos autores, os tutores/professores podem utilizar o mapa conceitual de domínio criado pelos designers especialistas para projetar materiais adaptativos para os alunos. Assim, o mapa conceitual serve como uma ferramenta de diagnóstico que compara o mapa atual do sistema e o mapa construído pelo aluno, para que a partir de então, o tutor/professor possa construir um material de aprendizagem adaptativo que visa corrigir o gargalo existente na aprendizagem.

Para Yan [2009] existe uma necessidade crescente de oferta de aprendizagem personalizada em sites de $e$-learning. Em sua pesquisa, o autor investiga como os fatores de cognição afetam a preferência do estudante pelo OA. O mapa cognitivo serve como um modelo do conhecimento sobre as características do OA, no qual deve ser baseado nas percepções e no grau de satisfação dos estudantes, representadas nos conceitos dos mapas cognitivos.

No artigo de Wu, Miao e Chen [2012] a correspondência dos conceitos investigados se dá por meio da utilização de um Fuzzy Cognitive Map (FCM) em um Sistema Learning Companion (SLC) para detectar OA interessantes, adaptados ao nível atual de conhecimento dos estudantes. $\mathrm{Na}$ pesquisa a preocupação é a orientação da aprendizagem em Ambientes de Aprendizagem Virtual (VLE). Complementar às pesquisas realizadas com Fuzzy Cognitive Map, Stach, Kurgan e Pedrycz [2010] apresentam modelos diferentes de projetos de FCM com objetivos de qualificação das informações e otimização dos mapas.

Wan e Niu [2016] em suas pesquisas, propõem uma abordagem de recomendação orientada para o aluno com base no mapeamento de conceitos mistos e no algoritmo imunológico (IA), criando modelos universais para aprendizes e OA, respectivamente, para posteriormente aplicar o mapeamento misto para assimilar seus atributos.

Askar e Altun [2009] descrevem em sua investigação como as representações ontológicas desempenham um papel na criação de orientação de navegação personalizada para permitir a visualização de habilidades cognitivas e fornecer feedback de navegação útil para os alunos. De modo que sejam atendidas a avaliação da representação das expectativas dos estudantes na aprendizagem por meio de OA. Desta forma, é proposto um novo método para identificar as expectativas de aprendizagem, através da determinação de conceitos de domínio.

Bruno et al [2012] propõem uma ferramenta baseada na web que permite o desenvolvimento e o fornecimento de OA generativos, em um sentido de reutilização e recontextualização em diferentes cenários, abrangendo uma aprendizagem combinada (híbrida). Deste modo, a ferramenta proposta pelos autores permite que os projetos de aprendizagem funcionem como estruturas construídas em XML, baseadas em mapas conceituais, atuando como uma camada de interação entre o OA, organizando o conteúdo disponibilizado. Nessa proposta, a operabilidade do objeto acontece online, em um navegador web que se adapta conforme os comandos recebidos, ou seja, de acordo com as necessidades e o estilo de aprendizagem do aluno. Assim, o objeto é personalizado conforme o perfil do estudante e molda-se para o estilo de aprendizagem dele. Como consequência, a experiência traz mais qualidade ao objeto e constante aprimoramento e atualização dele.
Realização:

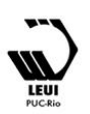




\section{$16^{\circ}$ \\ ERGODESIGN USIHC CINAHPA}

Logo, os estudos selecionados contribuem, para recomendações personalizadas de OA, através da modelagem de mapas conceituais que detectam preferências, informações relevantes, entre outras análises complexas para a gestão do aprendizado. Visto que, verificou-se com a análise dos resultados, obtidos nas investigações selecionadas, que os OA mais expressivos, reconhecidos nos diferentes espaços $e$-learning, são resultantes de informações imprescindíveis produzidas na modelagem dos mapas conceituais.

\section{Considerações Finais}

O estudo, em atendimento ao objetivo principal da sua investigação, apresentou a correspondência entre OA e mapas conceituais, através de uma RSL, por meio das publicações que relacionam o tema.

Verificou-se que apesar da importância do uso dos mapas conceituais na gestão do conhecimento, poucos autores tratam a relação do tema concomitantemente com as pesquisas sobre OA, visto que, com a localização dos estudos, percebeu-se que tecnologias adaptativas podem emergir em contribuição ao acesso mais personalizado de estudantes à aprendizagem.

Como delimitações deste estudo, notou-se que outras variáveis poderiam ser exploradas, na RSL, como a terminologia "ontologia", que contribuiria com a ampliação da localização de outros estudos relacionados com a temática pesquisada.

Por fim, sugere-se a continuação de estudos que identifiquem práticas relacionando os aspectos da aprendizagem personalizada, nas quais é possível modelar mapas conceituais para reconhecer os OA mais significativos e representações de conhecimentos relevantes ao estudante.

\section{Referências Bibliográficas}

ASKAR, P.; ALTUN, A. CogSkillnet: An Ontology-Based Representation of Cognitive Skills. Educational Technology \& Society, v. 12, n. 2, p. 240-253, 2009. ISSN 1436-4522. $16^{\circ}$ Ergodesign - Congresso Internacional de Ergonomia e Usabilidade de Interfaces Humano Tecnológica: Produto, Informações Ambientes Construídos e Transporte

$16^{\circ}$ USIHC - Congresso Internacional de Ergonomia e Usabilidade de Interfaces Humano Computador

CINAHPA | 2017 - Congresso Internacional de Ambientes Hipermídia para Aprendizagem.

BRUNO, F. B. et al. Web-based learning design tool. Campus-Wide Information Systems, v. 29, n. 4, p. 201-212, 2012. ISSN 1065-0741.

CHEN, N.S. et al. Mining e-Learning domain concept map from academic articles. Computers \& Education, v. 50, n. 3, p. 1009-1021, 2008. ISSN 0360-1315.

CHURCHILL, D. Towards a useful classification of learning objects. IN: Educational Technology Research and Development. Out. 2007, v. 55, n. 5, p. 479-497.Disponível em:

<https://link.springer.com/article/10.1007\%2Fs114 23-006-9000-y>. Acesso em: 01 mar. 2017.

\section{COCHRANE, B. Como fazer uma Revisão}

Sistemática Cochrane. Disponível em: $<$ http://brazil.cochrane.org/como-fazer-umarevis\%C3\%A3o-sistem\%C3\%A1 tica-cochrane>. Acesso em: 25 fev. 2017.

FERREIRA, J. F. C.; REZENDE, D. V. Objetos de aprendizagem: criatividade aplicada aos processo educativos. p. 11-44. IN: ULBRICHT, V. R.; VANZIN, T.; SILVA, A. R. L.; BATISTA, C. $R$. Contribuições da criatividade em diferentes áreas do conhecimento. São Paulo: Pimenta Cultural, 2013.

GOMES, Maria João. E-learning: reflexões em torno do conceito. 2005.

MACEDO, C. M. S. Diretrizes para criação de objetos de aprendizagem acessíveis. 2010. Tese (Doutorado). Universidade Federal de Santa Catarina de Engenharia e Gestão do Conhecimento. Campus Florianópolis, Santa Catarina, 2010. Disponível em: $<$ https://repositorio.ufsc.br/bitstream/handle/12345 6789/94396/288186.pdf? sequence $=1$ \&isAllowed $=$ y >. Acesso em: 24 fev. 2017. 


\section{$16^{\circ}$ \\ ERGODESIGN USIHC CINAHPA}

$16^{\circ}$ Ergodesign - Congresso Internacional de Ergonomia e Usabilidade de Interfaces Humano Tecnológica: Produto, Informações Ambientes Construídos e Transporte

$16^{\circ}$ USIHC - Congresso Internacional de Ergonomia e Usabilidade de Interfaces Humano Computador

CINAHPA | 2017 - Congresso Internacional de Ambientes Hipermídia para Aprendizagem.
MENDONÇA, M.; ARRUDA, L. V. R.; NEVES JR, F. Mapas cognitivos aplicados ao controle qualitativo de processos. IN: IX Simpósio Brasileiro de Automação Inteligente, 2009, Brasília. Anais. Campinas: Sociedade Brasileira de Automática, 2009. v. 1. p. 1-6.

MENOLLI, A. et al. Ambiente Colaborativo Semântico Voltado à Aprendizagem Organizacional para Empresas de Desenvolvimento de Software. XIII Simpósio Brasileiro de Qualidade de Software. 2014. p. 355369. Disponível em:

$<$ http://www.lbd.dcc.ufmg.br/colecoes/sbqs/2014/0 28.pdf >. Acesso em: 11 mar. 2017.

MOREIRA, M. A. Mapas conceituais e aprendizagem significativa. p. 41-54. IN: Moreira, M. A. Aprendizagem significativa, organizadores prévios, mapas conceituais, diagramas $V$ e unidades de ensino potencialmente significativas. Porto Alegre: UFRGS, 2012. Disponível em: 〈https://goo.gl/JuAQ6e〉. Acesso em: 10 mar. 2017.

OKADA, A. L. P. Cartografia Investigativa: interfaces epistemologicas comunicacionais para mapear conhecimento em projetos de pesquisa. 2006. Tese (Doutorado). Pontifícia Universidade Católica de São Paulo. São Paulo, 2006.

Disponível em: <

https://tede2.pucsp.br/handle/handle/9889>.

Acesso em: 18 fev. 2017.

OKADA, A. L. P. Mapas Conceituais em projetos e atividades pedagógicas. IN: MORAES, U. C.

Tecnologia Educacional e Aprendizagem: o uso dos recursos digitais. Saulo: Livro Pronto, 2007. Disponível em: <http://oro.open.ac.uk/41744/1/c11lpronto2008.pd f $>$. Acesso em: 27 fev. 2017.
OKADA, A. L. P. Mapas do conhecimento com recursos educacionais abertos aplicados à coaprendizagem baseada em coinvestigação. IN: TORRES, P. L. (Org.). Complexidade: redes e conexões na produção do conhecimento. Curitiba: SENARPR, 2014. v. 1. p. 213-238.

OKADA, A. L. P.; SANTOS, E. O. Mapeando redes de informações com uso de software: uma experiência de pesquisa e docência em EAD online. Revista Digital de Tecnologia Educacional e Educação a Distância. v. 2. n. 1. Outubro, 2005. ISSN 1808-1061. Disponível em: <http://www.pucsp.br/tead/n2/pdf/artigo2.pdf > Acesso em: 20 fev. 2017.

PACHECO, R. L. Avaliação formativa continuada do processo educativo em engenharia usando mapas cognitivos difusos. 2005. 297 f. Tese (Doutorado). Universidade Federal de Santa Catarina, Centro Tecnológico. Programa de Pós-Graduação em Engenharia Elétrica, Florianópolis, Santa Catarina, 2005.

\section{RODRIGUES, K. G.; BARNI, E. M. Mapas} conceituais: potencializador da aprendizagem na modalidade de ensino a distância do curso superior de Pedagogia de uma Instituição de Curitiba. IX Congresso Nacional de Educação - EDUCERE, III Encontro Sul Brasileiro de Psicopedagogia. PUCPR: 2009. Disponível em: <http://www.pucpr.br/eventos/educere/educere200 9/anais/pdf/3537_2126.pdf $>$. Acesso em: 05 mar. 2017.

STACH, W.; KURGAN, L.; PEDRYCZ, W. A divide and conquer method for learning large Fuzzy Cognitive Maps. Fuzzy Sets and Systems, v. 161 , n. 19, p. 2515-2532, 2010. ISSN 01650114 .

VON RAESFELD-PORRAS, P. A. 2000.

Campestre: Aplicación de mapas cognitivos
Realização:

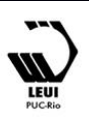




\section{$16^{\circ}$ \\ ERGODESIGN USIHC CINAHPA}

$16^{\circ}$ Ergodesign - Congresso Internacional de Ergonomia e Usabilidade de Interfaces Humano Tecnológica: Produto, Informações Ambientes Construídos e Transporte

$16^{\circ}$ USIHC - Congresso Internacional de Ergonomia e Usabilidade de Interfaces Humano Computador

CINAHPA | 2017 - Congresso Internacional de Ambientes Hipermídia para Aprendizagem.

difusos a VRML en un ambiente virtual. 2000.

Trabalho de Conclusão de Curso (Graduação).

Departamento de Ingeniería en Sistemas

Computacionales, Escuela de Ingeniería,

Universidad de las Américas. Puebla, mai, 2000.

WAN, S.; NIU, Z. A learner oriented learning recommendation approach based on mixed concept mapping and immune algorithm.

Knowledge-Based Systems, v. 103, p. 28-40, 2016. ISSN 0950-7051.

WU, Q.; MIAO, C.; CHEN, Z. A curious learning companion in Virtual Learning Environment. WCCI 2012 IEEE World Congress on Computationallnteliigence. p. 1015, jun. 2012. Brisbane, Australia.

YAN, C. A Cognition Inference-based Approach for Learning Object

Recommendation in E-Learning. Shanghai:

Business School, 2009. 